Jeremy J. Holland* and Elena Nichele

\title{
An ideological content analysis of corporate manifestos: A foundational document approach
}

\author{
DOI 10.1515/sem-2015-0115
}

\begin{abstract}
This project involves a socio-linguistic look at corporate discourse in the form of "mission statements." The analysis is performed by utilizing the foundational document model (FDM) as a theoretical framework for performing ideological content analyses. The FDM is a semantic grammatical model consisting of five sociological categories (ethical norms, folklore narrative, utopian schemes, strategic planning, and role attribution). Stark contrasts are observed between manifestos produced by the two most successful companies in the soft beverage industry (Coca-Cola and PepsiCo.). The comparative analysis performed in this study shows great potential regarding a possible extension and application of the content-analytical framework for those primary texts used when mobilizing collective action.
\end{abstract}

Keywords: corporate discourse, critical discourse analysis, foundational document model, ideological content, mission statements, semantic grammar

\section{Introduction}

This article is a socio-linguistic look at corporate discourse in the form of "mission statements." The researchers use Holland's (2014) foundational document model (FDM), which acts as a theoretical framework for performing ideological content analyses. The FDM is a semantic grammatical model that consists of five sociological categories (ethical norms, folklore narrative, utopian schemes, strategic planning, and role attribution).

This textually-oriented model is applied to both PepsiCo. and Coca-Cola's "mission statements" to provide an ideological content analysis of these foundational texts published online (Coca-Cola Company, n.d.; PepsiCo, n.d). Viewing these statements from a discourse analytical approach, we consider them corporate manifestos that seek to provide a tidy statement of vision, values, and strategy. Our

\footnotetext{
*Corresponding author: Jeremy J. Holland, Department of Language and Linguistics, Lancaster University, 3 Vincent Street, Lancaster, Lancashire LA1 3BA, UK, E-mail: j.holland5@lancaster.ac.uk Elena Nichele, Department of Language and Linguistics, Lancaster University, Flat 5 House 79 Damson North Drive County Field Lancaster, Lancashire LA1 4YD, UK, E-mail: e.nichele@lancaster.ac.uk
} 
underlying assumption is that corporate manifestos are meant to speak to multiple audiences at once in order to mobilize all interested parties simultaneously (e.g., investors, employees, and consumers).

Foundational documents are defined as those texts that provide a pervasive cultural metanarrative for religious, political, social, and business organizations (Holland 2014). These texts are crucial in the makeup of "master frames" in society (Carroll and Ratner 1996). Benford and Snow (2000) describe master frames as interpretive conceptual orderings that are highly culturally resonant, and they show that these frames can be drawn upon in order to mobilize potential social movement activists. We hypothesize that these foundational texts provide the narrative backdrop to master frames and that they are necessary to provide participants in discourse communities a cohesive measure of role stability, ethical guidance, utopian visionary goals, and strategic coherence. The FDM has recently been used in consideration of revolutionary ideology within primary social movement texts. Our goal here is to show how this textually oriented analytical framework is applicable to corporate documents as well.

Yet, the FDM is not only concerned with ideological content, but also with higher orders of a text's grammatical layout, what Fairclough (1992: 77) calls the "architecture of texts." Thus, application of this discourse model acts as a collective action grammar intending to reveal how semantic units are structured within texts produced by the soft beverage industry. Discourse structure is considered in the model by showing how ideational strands of meaning are positioned within text and interact with one another.

\section{Social construction and structural analysis}

Two positions are axiomatic for this kind of socio-semiotic analysis: i) the social constructivist position of reality creation; and ii) structural approaches that provide replicable, versatile, and helpful frameworks for categorizing and interpreting textual meaning. Within the social constructivist perspective, discourse is both actively constituting and constrained by institutional structures (Burr 2003). By understanding reality creation as a dialectical project of social construction, application of the FDM can broadly be considered as a deconstruction of cultural texts. Hence the FDM is "deconstructive" in the sense that it intentionally seeks to name, isolate, and categorize dominant signifiers within selected discourse formations. Dominant signifiers are those ideational elements that make up the most stable elements of that social group's reality creation efforts (collective identity, ethical norms, and strategic themes). 
In our case, the dominant signifiers under consideration are those present in corporate organizational online texts. The primary goal of this analysis is to pinpoint and unravel these important signifiers, those that are used by business elites who are fervently attempting to construct identities, values, and attitudes in order to establish and sustain a corporate cultural edifice. To demonstrate the FDM, we have chosen two globally leading corporations in the beverage industry: the Coca-Cola Company and PepsiCo. After performing the ideological content analysis of each separately, we then compare the findings in order to understand what similarities and differences exist between the two cases. Going forward, the three main questions guiding our investigation of these corporate manifestos are the following:

(1) How can ideological content and semantic structure be systematically described using a text analytical approach?

(2) Is there any correspondence between the two companies' successful communication of their organizational cultures and the semiotic formulations of their mission, vision, and values?

(3) What main similarities and differences can be noticed in the mission statements of these two direct rivals leading the soft beverage market?

\section{The current state of mission statement analysis}

The texts under consideration for this study are sections of corporate websites that we consider to be comprehensive mission statements. We based our bibliographical research on works that consider these types of primary texts from both linguistic and sociological perspectives. Hence, we have paid special attention to intertextuality, institutional discourse, and how corporate communication is deeply impacted by linguistic choices - especially in terms of persuasive power.

A sense of mission plays a critical role for companies, both externally and internally (Collins and Porras 1995, 1997). It presents businesses to the public, but it also serves the purpose of determining their collective identity, currently and as projected in the future (Hongwei 2012). Some experts maintain that an inadequately formulated mission statement could, eventually, determine a companies' failure (Beaver 2000). Khalifa (2012: 237) conceives of mission statement analysis as an attempt to present a model that "represents a particular approach of how to use a system of guiding statements ... to help manage for lasting success." Here he defines the object of analysis as a fixed system of statements. Yet after the review of three prominent models for deconstructing the mission statement (i.e., the vision framework, the Ashridge mission model, and Lipton's 
model of organizational vision), no one model can claim more legitimacy than the next. Khalifa (2012: 240) discerns that the authors of these influential corporate discourse models "admit ... that their formulations are not found explicitly and formally written in practice in the forms they advocate."

The FDM can remedy this lack of theoretical consistency by not seeking to impose a foreign framework of ideals that should be included (or excluded) in a mission statement, and instead provides a framework of socio-semantic categories that takes into consideration what is already present in the text itself. While each of these previous corporate discourse analysts do not claim that their model is found explicitly in a formal manner within any organization's mission statement, the foundational document framework can be used to parse constituent units of meaning already present in the texts, those ideational units that can be found in all such collective action oriented documents.

\section{A socio-semiotic theoretical framework}

The methodology informing this project is based on Holland's (2014) foundational document model. This is a model meant to act as an ideological content analysis and takes strong cues from the critical discourse analysis theoretical framework of Norman Fairclough (2010) and the structural anthropology of Claude Lévi-Strauss (1963). The combination of these innovative frameworks enables the FDM to function as a kind of critical sociological structuralism. The analysis below can be considered "critical" in the sense that we are trying to point out what elements in the mission statement make up the taken-for-granted, commonsensical, and hence ideological strands that are interwoven and running through the text.

In order to operationalize a replicable textual model, the FDM introduces five socio-semantic categories that are meant to capture constituent ideational units of meaning within the foundational text. These units of meaning are seen as interwoven ideological strands, that, when acting in combinations, make up the frame packages of corporate heads (or any cognizant collective action frame producer). In discourse production these ideological elements are spliced and pieced together to create comprehensive and interpretive frameworks that are presented to the text consumer. Briefly, the five socio-semantic categories in play are as follows:

- Ethical Norms: These are the portions of texts that emphasize the needed moral point of the hour (Audi 2009). Moral values are usually deployed to boost the image of the company (e.g., green energy consumption) or to inspire employees and investors to commit to the company's fiscal goals (e.g., praising work ethic and integrity). 
- Folklore Narrative: This is the ideological strand that draws most closely on the concept of manifest intertextuality (Fairclough 1995). When seeking to trace this strand the analyst must become acutely aware of the historical, and therefore contingent, situation within an organizational culture. Much of this work is an attempt to show how previous texts are recontextualized for the current situation (e.g., Coke's 2020 Vision). Discursive transformations, mutations, and annihilations can be made visible here.

- Utopian Schemes: These high-minded visions are usually claims made about the future success of the organization, and are repeatedly put before the potential adherents of a social group in order to inspire them to persist in the face of much opposition, or in the corporate culture - fierce competition (e.g., winning). This category is determinedly teleological and reinforces the view that most organizations operate on the fiction of an idealized future state of equilibrium and harmony (Plum 1974).

- Strategic Planning: This is the most praxis-centered category, representing pieces of texts that actually spell out particular actions to which discourse consumers should adhere (e.g., bring in new perspectives). This is the most practical rhetoric contained within corporate manifestoes, indicating to the text consumer the proper fields of battle, strategies for winning, and tactics for execution. Although, one must be aware in these types of public corporate manifestos that there is not much more than a nod (through excessive verbiage) to strategy, and not much in the way of substance.

- Role Attribution: Within much critical discourse literature there has been a consistent emphasis on in/out group role attribution (Koller 2008; van Dijk 1998). The foundational document approach continues to investigate this emphasis on the polarization of roles. Corporate texts are produced with the intention of mobilizing potential adherents into the ranks of an organizational structure. A key difference between social movement texts versus corporate foundational texts is that social movement texts are constantly presenting reality as a world of contention where movement actors are up against welldefined and targeted enemies. By contrast, in corporate texts the out-group is so back grounded as to be almost completely invisible (e.g. the world, trends and forces, and the market place).

Hence, in relation to the jargon employed in the current management literature on mission statements, the above mentioned categories are commensurate in that: (1) values are ethical (2) corporate texts draw on cultural folklore, (3) vision alludes to utopia, (4) mission indicates strategy, and (5) identity has to do with the taking on of various roles. To demonstrate this ideological content analysis, 
we chose the current online mission statements of the Coca-Cola and Pepsi corporations (Coca-Cola Company, n.d.; PepsiCo, n.d). This allows us to consider two separate foundational texts from leaders in the same industry, and enact a comparative approach between the two.

\section{FDM content analysis instructions}

Below we perform an ideological content analysis by displaying the first round coding to the introductions of two corporate manifestos. The subtext in the FDM is marked off by five broad theoretical categories, which are abbreviated as ethical norms (ETH), folklore narrative (FLK), utopian schemes (UTP), strategic planning (STRT), and role attribution (ROLE). These major categories are able to pinpoint and reassemble ideologically relevant sections of the text in order to form a new content world (Lieblich et al. 1998). In the FDM these categories are predefined by the integration of multiple social theories, which prompt the analyst to search for ideational specifics. Below we place categorical abbreviations of the five major categories within the text of the manifestos so that the reader will better understand how these ideological strands are positioned within and among one another.

With this categorical operationalization in the FDM, the analyst is expected to read the subtext provided by the five major ideological categories as openly as possible and to craft subcategories that emerge from the reading (e.g., ROLE shareholders). This step in the content analysis involves "careful reading, suggesting categories, sorting the subtext into categories, generating ideas for additional categories or for the refinement of the existing ones, and so on" (Lieblich et al. 1998: 113). Therefore, the FDM uses both predefined theory-based major categories (deductive) and subcategories suggested by the text itself (inductive). While the FDM consists of five broad categories that are fairly straightforward to implement during text analysis, these broad categories do not capture the ideological complexity of the text. This is why subcategories that inductively emerge from the text are so important, because they enable the analyst to perform a meticulous sorting of the textual material in a way that retains thematic richness and variation.

Sorting textual sections into the major categories involves assigning phrases or clauses to relevant ideational slots. At this step, the five larger categories allow the analyst to come to the text with a predetermined theoretical grid, directing her/him to make relatively straightforward sorting decisions. This broad categorical constraint ensures that the FDM enjoys a high level of methodological replicability. This sorting practice can be done within a research group independently to allow for inter-judge reliability, or together creating a 
more poignant interdisciplinary sensitivity to textual meaning. To ensure the valid assignment of a code the analyst should assign no more than one code to each portion of the text ensuring mutually exclusive categorization.

Corporate presentations, like the rest of language, are made up of integral semantic units of analysis. Because these ideological units exist at a higher and more complex linguistic order, they must be seen to consist of ideational clusters residing in cognitive pockets of meaning (Hart 2010). Using this multidimensional typology that is able to pinpoint ideological components in texts, the analyst is able to compare more precisely the contents of corporate discourses across specific industries. Specifically, this enables the analyst to identify the differences and similarities in each group's ideological emphases and persuasive techniques.

\section{Demonstration of FDM content analysis}

In order to demonstrate the coding decisions that must be made, we include the introductions of both corporate manifestoes here for your consideration.

\subsection{Coca-Cola introduction (first round coding)}

The world (ROLE) is changing (ETH) all around us (ROLE). To continue to thrive (UTP) as a business (ROLE) over the next ten years and beyond (UTP), we (ROLE) must look ahead (UTP), understand (STRT) the trends and forces (ROLE) that will shape our business (ROLE) in the future (UTP) and move swiftly to prepare (STRT) for what's to come (ETH). We (ROLE) must get ready (STRT) for tomorrow today. That's what our (ROLE) 2020 Vision (FLK) is all about. It creates (FLK) a long-term destination (UTP) for our business (ROLE) and provides us (ROLE) with a "Roadmap" (STRT) for winning together with our (ROLE) bottling partners (ROLE).

\subsection{Pepsi Co. introduction (first round coding)}

At Pepsi Co, (ROLE) we (ROLE) believe being a responsible (ETH) corporate citizen (ROLE) is not only the right thing to do (ETH), but the right thing to do (ETH) for our business (ROLE). Our (ROLE) mission (STRT) is to be the world's premier (UTP) consumer products company (ROLE) focused on convenient foods and beverages (STRT). We (ROLE) seek to produce financial rewards (STRT) to investors (ROLE) as we (ROLE) provide opportunities (STRT) for growth and enrichment (UTP) to our 
(ROLE) employees (ROLE), our (ROLE) business partners (ROLE) and the communities (ROLE) in which we (ROLE) operate. And in everything we (ROLE) do, we (ROLE) strive for honesty (ETH), fairness (ETH) and integrity (ETH).

After the analyst has completed the first round of coding on the entire document with the major socio-semantic categories, s/he should move on to the task of sub-categorization in order to explore how these five ideological strands are woven throughout the text. We will proceed by showing our sub-categorical results for both corporate manifestos and make comparisons between them. Below, each subcategory is underlined with the number of times this category appears in the document (e.g., honesty (8)). Assigned to each subcategory is any word or phrase in the text that was sorted into that category.

\subsection{Ethical norms (second round coding)}

PepsiCo.

\begin{tabular}{|c|c|c|c|}
\hline $\begin{array}{l}\text { honesty (8) } \\
\text { straightforward } \\
\text { tell the whole story } \\
\text { honest } \\
\text { candor } \\
\text { truth } \\
\text { accurate } \\
\text { clear }\end{array}$ & $\begin{array}{ll}\text { commitment (7) } & \frac{t r}{\text { to build }} \\
\text { committed } & \text { in } \\
\text { commitment } & \text { a } \\
\text { walking the talk } & \mathrm{c} \\
\text { following through } & \mathrm{p} \\
\text { commitment } & \mathrm{e} \\
& \mathrm{w} \\
& \end{array}$ & $\begin{array}{l}\text { trust }(7) \\
\text { integrity } \\
\text { build trust } \\
\text { accountable } \\
\text { confidence } \\
\text { placed in us } \\
\text { entrusted } \\
\text { with resources } \\
\text { strengthen that trust }\end{array}$ & $\begin{array}{l}\text { diversity (6) } \\
\text { inclusion } \\
\text { backgrounds } \\
\text { traits } \\
\text { ways of thinking } \\
\text { diversity }\end{array}$ \\
\hline envir. stewardship (6) & responsibility (6) & fund. principles (3) & $\frac{\text { quality }}{\text { of products (3) }}$ \\
\hline $\begin{array}{l}\text { positive imprint } \\
\text { environmental issues } \\
\text { envir. responsible } \\
\text { right thing to do }\end{array}$ & $\begin{array}{l}\text { acting responsibly } \\
\text { good } \\
\text { comm.. are } \\
\text { understood } \\
\text { to meet needs } \\
\text { proper governance }\end{array}$ & $\begin{array}{l}\text { guiding principles } \\
\text { six guiding } \\
\text { principles }\end{array}$ & $\begin{array}{l}\text { proud } \\
\text { standards }\end{array}$ \\
\hline
\end{tabular}

\begin{tabular}{|c|c|c|}
\hline value (3) & care (2) & fairness (1) \\
\hline $\begin{array}{l}\text { on results } \\
\text { of teamwork }\end{array}$ & respect (2) & freedom (1) \\
\hline
\end{tabular}




\section{Coca-Cola}

responsibility (9)

overall responsibilities

behaviors required

integrity

committed mind/heart

accountability

accountable for action

be a responsible

citizen

overall responsibilities diversity (3) courage (2) envir. stewardship (2)

inclusive to change make a difference

collaboration course sustainable

diversity communities

The most drastic contrast between the two corporate manifestos can be seen under the ethical norm category. Out of the fourteen ethical norms identified, only three overlap. Both companies emphasize responsibility (Pepsi six times and Coke nine). Pepsi encourages the collective "we" to act responsibly and make sure that "communities are understood." In contrast Coke stresses more individual responsibility, calling attention to the "attitudes and behaviors required" of employees in whatever station they may occupy within the company. Consulting the content analysis above, the analyst can see that Coke's individual focus emphasizes accountability, commitment, and integrity, while Pepsi's collective focus emphasizes mutual understanding, meeting other's needs, and participation in the "proper governance" of the company. In this way, Coke's foundational text acts as a manifesto of competition and personal responsibility, while Pepsi's document acts as a manifesto of cooperation and mutual trust.

A point of similarity is the concern over environmental stewardship (Pepsi six and Coke two). Pepsi poses as an "environmentally responsible" organization that intends to leave a "positive imprint" on communities, and strives to do the right thing as a "corporate citizen." Coke pays homage to this image, but its eco-ethical stance is more of a footnote, only briefly mentioning that employees should seek to "make a difference" and "become more eco-friendly" by "helping sustainable communities."

The last point of ethical comparison comes under the "diversity" subcategory. Again, Pepsi assigns more textual space to ethics with diversity mentioned six times (versus Coke's three). Both documents mention the importance of an inclusive working environment, but Pepsi goes on further to explain that this inclusive atmosphere must be fostered by intentionally valuing diverse "backgrounds," "traits," and "ways of thinking." The only ethical norm not mentioned 
by Pepsi but present in Coke is courage. This occurs because of Coke's emphasis on competition. Coke envisions a courageous company, one that has to continually be willing to take risks in an economic climate that is hard to decipher.

On the other hand, Pepsi's manifesto contains nine norms unaccounted for in the Coke document which include honesty, commitment, trust, purpose, quality of products, value, care, respect, fairness, and freedom. Pepsi strongly emphasizes collective honesty, commitment, and trust, calling for the corporate entity as a whole to act in a "straightforward" manner, able "to tell the whole story" and thus limit deception. This focus on commitment goes hand-in-hand with the emphasis on trust, noting that the company must "follow through on our commitment" and "build trust” by taking seriously the "confidence placed in us."

\subsection{Folklore narratives (second round coding)}

PepsiCo.

performance $w /$ purpose (4)

purpose agenda

company performance

\section{Coca-Cola}

2020 vision (4)

it creates a long term destination

serves as a framework and guides

The two folklore narratives running through and very much informing the corporate manifestos are Pepsi's "Performance with Purpose” and Coke’s "2020 Vision." Pepsi's Performance with Purpose campaign began in 2007 with a 44 page "sustainability report" explicitly targeting: i) human sustainability; ii) environmental sustainability; and iii) talent sustainability. Coke’s 2020 Vision was created in 2009 and is presented to its "bottling partners" as a "roadmap for winning together." The contrast between the framing of these two long-term strategy plans is immediately obvious. Pepsi couches its agenda in the language of sustainability whereas Coke decidedly uses a more competitive frame, that of participating on a winning team. These highly differing framing efforts provide the key background concepts that are taken up and expounded in the corporate manifestos.

Within the first paragraph of Coke's manifesto, the 2020 Vision is proclaimed as creating "a long term destination" for the business, and incorporates the slogan that serves as a header for the actual 2020 Vision document: “A roadmap for winning together with our bottling partners.” Coke’s manifesto continues to reference the 
2020 Vision throughout, mainly by using the same content headings as the document itself. The tripartite company missions "to refresh," "to inspire," and "to create" are lifted straight from the 2020 vision with little else added to them except that they are "enduring" and serve as "the standard."

The vision section of the manifesto is almost exactly the same as in the 2020 Vision document, except that the order of the "six P's" mentioned differ in each document. In the 2020 Vision the order is: profit, people, portfolio, partners, planet, and productivity, whereas in the manifesto profit moves down to the fifth position while all the other P's remain static. This movement of profit down the $\mathrm{P}$ chain is understandable as the language included in the 2020 Vision seems aimed at corporate heads using the possessive pronoun such as, "Inspire our people to be passionate ambassadors for our brand." Yet in the manifesto, Coke seems to be fleshing out the 2020 Vision in a slightly more inclusively hortatory manner, all while maintaining that hierarchical vibe of talking mostly to the company's main decision makers. Hence, the people category rises to the top, and while both documents state (under the people category) that they intend to provide a "great place to work," the manifesto adds, "where people are inspired to be the best they can be." The rest of Coke's manifesto is spent describing in more detail a number of slogans found running across the bottom of the 2020 Vision document (e.g., live our values, focus on the market, work smart, act like owners, and be the brand). These slogans are taken up as subheadings for rest of the manifesto and are given more concrete substance through bullet point exhortations (e.g., Reward our people for taking risks ...).

In 2012 Pepsi re-evaluated its Performance with Purpose agenda with input from the communities they work in and businesses they supply. On the company web page under the tab "Our Performance with Purpose Goals" the site states: "This goalsetting process focused our efforts as we strive to deliver great performance by doing the right things for people and communities around the world." This focus on performance is seeking to strike a balance between human talent, environmental sustainability, and financial growth. The incorporation of these three performance agenda emphases are not as blatant as Coke's method of lifting slogans directly from the 2020 Vision and placing them as subheadings within their manifesto.

Instead, Pepsi weaves these three aspects throughout its manifesto as a narrative about a company that cares deeply about people, the environment, and longterm financial growth. The only direct mention of the 44-page Performance with Purpose document incorporates two of these emphases in the same sentence: "At PepsiCo, we're committed to achieving business and financial success while leaving a positive imprint on society - delivering what we call Performance with Purpose.” Pepsi's manifesto seeks to present a narrative of caring for people, the planet, and their company. They are interested in presenting a face of consideration and 
compassion, whereas Coke downplays these more communal elements and focuses more on winning market share, individual success, and personal accountability to the company. Given the companies' position in the soft beverage market, there seems to be a strategy of differentiation from each other at work here.

\subsection{Utopian schemes (second round coding)}

PepsiCo.

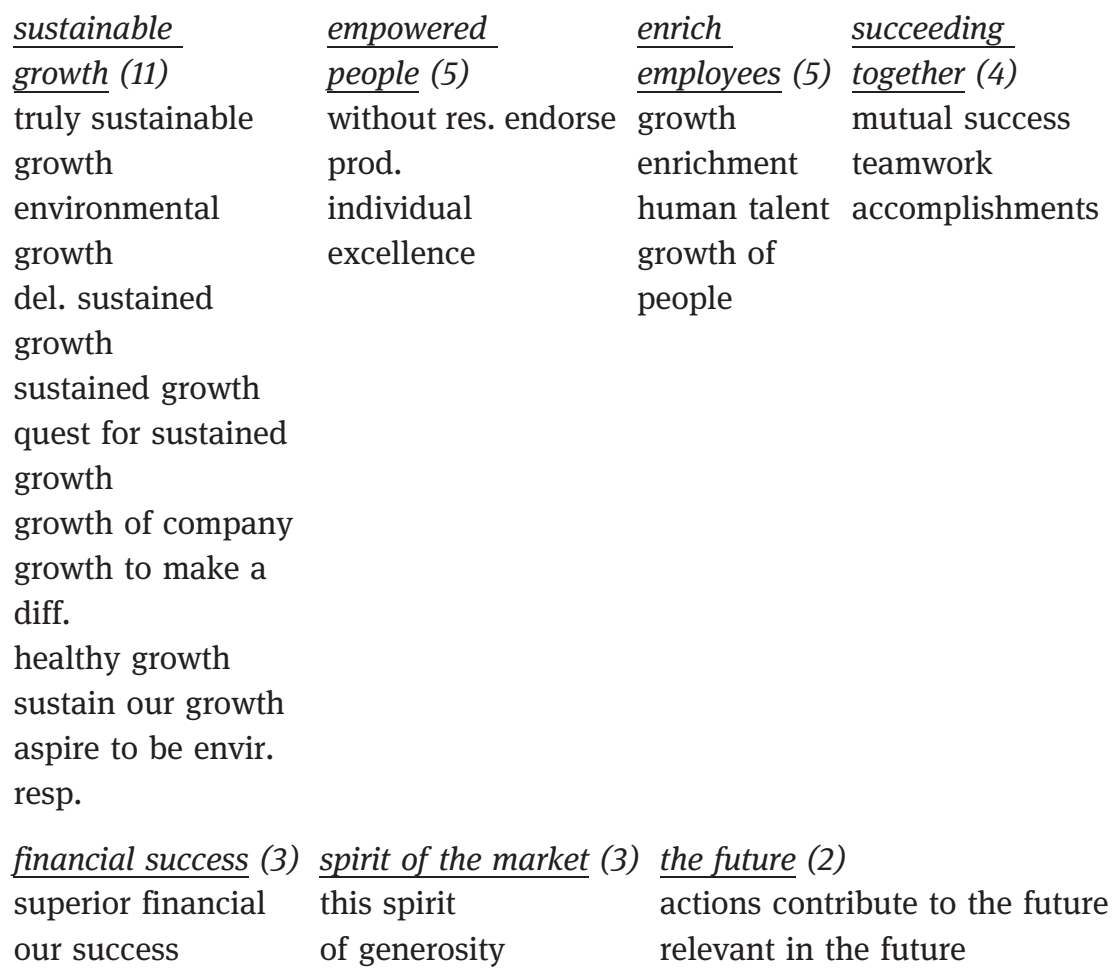

\section{Coca-Cola}

a thriving future (5) satisfy desires (2) inspire optimism (2) create value (2) continue to thrive refresh the world inspire optimism look ahead satisfy people's inspire creativity, opt. the future desires a better future long term destination 
sustainable and quality growth (2)

support sustainable communities

The projection into the future dominates Coke's text, combined with the sensation that the sooner these objectives are achieved the better the impact it will have on the corporation's survival and, hopefully, its profitability. In fact, both a renovated sense of evolution and future projection can be noticed which is reiterated and enriched throughout the whole text. Being unforeseeable, this new evolution can be identified as a threat for the company's survival. For this reason, the imperative to "look ahead" translates into a protection from it and is proposed with the modal verb "must" to convey that sense of obligation and urgency previously mentioned. Past successes appear to act both as reassurance and encouragement in this situation. Additionally, the future projected is undefined and this transmits a sensation of permanent victory and reinforces the encouraging message. Moreover, "shape" alludes to the impact that this ongoing modification will have on the organization, making it clear from the beginning that this would not be lethal.

Indeed, death can be avoided through an accurate "preparation" that is supposed to be incremental and needed, as underlined by "move swiftly." The "Mission" paragraph opens with a reference to the "Roadmap," described as beginning with the mission itself. This might allude to the fact that this important corporation's pillar constitutes the first step of the plan of future actions that the company has delineated. In this sense, the mission could therefore be interpreted as the departure point from which the future of this organization will start, at least as its members depict it. The verb "start" signals the beginning of the future projection, incorporating two factors that predominate in the entire text. Right after that, the long-lasting characteristic of it is pointed out, reinforcing previous descriptions once again. The adjective "enduring" is, indeed, used more than once to refer to the "Roadmap" and it is then employed also for the "Mission" which comprehensibly shares the same features, being part of it.

This final concept may be ultimately referring to transparency and manageability of the task, given the skills and abilities already attained and those which could be developed by the company in the short, medium and long term. To express this idea in an even stronger way, the future goals of the company are explained in detail (Lord 2011). All these objectives are evidently ambitious and abstract. The first statement carries the verb "to refresh" that has been recurring in Coca-Cola Company's slogan since the beginning of 1900's, especially in the US and Canada. In chronological order: 
- 1904: Delicious and refreshing

- 1924: Refresh yourself

- 1929: The pause that refreshes

- 1945: Passport to refreshment

- 1959: Be really refreshed

- 1961: What a refreshing new feeling

- 2010: Twist the cup to refreshment (Coca-Cola Company, n.d.)

This choice can be strictly associated with the idea of physical pleasure that this brand seems to be willing to promote its products with. The drink was therefore introduced from the very beginning of its presence on the market as a possibility to escape unpleasant situations, such as heat and stress, or boredom. For this reason, the refreshing function of the product has been paired first with taste ("delicious"), then with the concept of taking a break ("pause"), and finally with the idea of travelling ("passport"). All of these words have a deep connection with physical pleasure which is also personal ("yourself"). Additionally, this sensation is connoted also as innovative ("new") and as powerfully impacting and renovating lives ("twist the cup").

This aspect may be the motivation behind the use of short, essential statements that employ abstract and words that are deeply emotionally meaningful, including boosters ("really"). Finally, evaluating the long history of this corporation, the concept of innovation may be carrying a will to express its ability to keep competing at a high level, always adapting itself to changing conditions. In this sense, Coke seems to represent itself simultaneously as an old and new company, as it benefits from both its experience and its up-to-date mentality.

\subsection{Strategic planning (second round coding)}

PepsiCo.

$\begin{array}{llll}\begin{array}{lll}\text { financial rewards (8) } \\ \text { build shareholder }\end{array} & \begin{array}{ll}\text { maintain balance (4) } \\ \text { value }\end{array} & \begin{array}{l}\text { mission (3) } \\ \text { term }\end{array} & \begin{array}{l}\text { solutions (3) } \\ \text { achieving financial benefit }\end{array} \\ \begin{array}{lll}\text { weigh benefits } \\ \text { success }\end{array} & \begin{array}{l}\text { focus on food } \\ \text { and bev. }\end{array} & \begin{array}{l}\text { company } \\ \text { decision }\end{array} & \begin{array}{l}\text { understanding } \\ \text { customers }\end{array}\end{array}$


financial

performance

drive shareholder

value

identify market

opportunities

business decision

measuring success

envir, stewardship (2)

activities

addressing envir.

issues

Coca-Cola

work smart (7)

with urgency

efficiently

change when

needed

find ways solve

problems

learn what worked

build value

values (2)

as compass for

actions

how we behave ideas and

solutions

\begin{tabular}{|c|c|c|}
\hline teamwork (2) & win with & employee \\
\hline \multirow[t]{5}{*}{ working together } & diversity (2) & oppor. (2) \\
\hline & bring in new & \\
\hline & perspectives & proper \\
\hline & & governance (2) \\
\hline & & $\begin{array}{l}\text { purchase quality } \\
\text { product }\end{array}$ \\
\hline
\end{tabular}

six business roadmap (5) future planning (2)

needs (6)

people for winning prepare for future

portfolio starts with get ready for tomorrow

partners mission today

planet it

profit

productivity

In the strategic planning sections of both documents we surprisingly see a great reversal in emphasis where Pepsi takes on a more economically minded perspective and Coke zeros in on the individual employee's work ethic. Pepsi's major strategic emphases are to provide financial rewards for their investors, maintain a balance between short and long term gains, and to be a company that takes initiative in providing solutions that are beneficial to all concerned. In contrast, Coke's strategy sections are highly concerned to emphasize that 
workers should work smart by finding "better ways to solve problems" and to work "with urgency." This is the one category that breaks the trend, where Pepsi seems more concerned with shareholders and Coke seems more concerned with workers. Despite that fact, Pepsi still manages to include environmental stewardship and Coke stays on message emphasizing "mission" and "winning" within the strategic rhetoric.

It is our contention that these corporate foundational texts act as pseudostrategic documents. We say pseudo because the text producers (Pepsi more than Coke) try to exude a sense of concern for the local environment, the broader community, and society in general. Yet the real, exacting details about how the company will actually move forward in the next five to ten years is wholly absent. These mission statement type documents are also pseudo-strategic in the sense that the "strategic" portions of the text are meant more to advertise that there is, in fact, a strategy to potential employees, stockholders, and buyers than to reveal the intricacies of the company's next strategic move (Myers 1994). Hence, the document is void of specifics. This is like the difference between going to a pre-game pep rally and hearing the rhetoric of "winning" from coaches and players, and actually sitting in the locker room painstakingly going over every minutia of the playbook. It is in this sense that language is used as a tool for giving the possible client or nervous stakeholder a calming dose of strategic rhetoric.

\subsection{Role attribution (second round coding)}

PepsiCo.

\begin{tabular}{|c|c|c|c|}
\hline we (30) & our (26) & company (16) & shareholders (5) \\
\hline & & PepsiCo & investors \\
\hline & & consumer & business \\
\hline & & products co. & partners \\
\hline & & corporate citizen & constituents \\
\hline & & business & \\
\hline & & work place & \\
\hline \multirow[t]{4}{*}{ people (4) } & communities (3) & employees (2) & consumers (1) \\
\hline & products (3) & team & stewards (1) \\
\hline & society (3) & individual (2) & world (1) \\
\hline & others & us (2) & \\
\hline
\end{tabular}


Coca-Cola

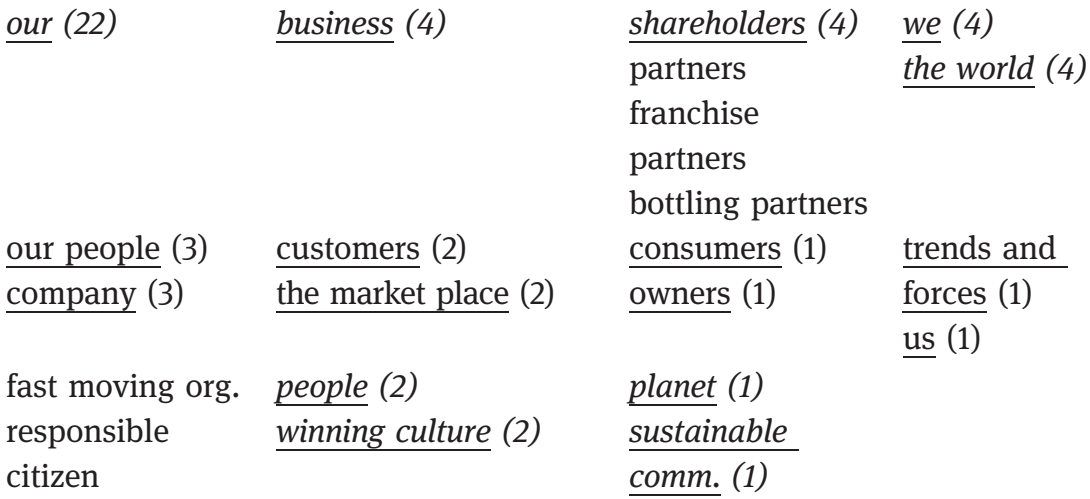

The role attribution category served as the category of most overlap between the corporate foundational texts. To be more precise, Coke delineates 58 actors in total: the adjective "our" constitutes the most frequent in the text, with its 22 appearances. Numerically, the "business," the collective "we," the "world" around it and its stakeholders follow with 4 presences each. The corporation is also defined under the word "company" twice, particularly alluding at its efficiency and social responsibility. In detail, the first person plural can be considered as a synonym of the corporation, where the pronoun helps to identify it as a unique entity which comprises several individuals working together to achieve the same objectives (Koller 2009). The same collective is expressed in different ways throughout the text, once using the pronoun "us," employing the expression "our people" three times or just "people" twice. Semantically, these roles may all be considered as perfect substitutes among each other, even if with slight variations. The presence of an additional element signaling possession, indeed, reinforces the message of a shared background and vision (Kelly-Holmes and Mautner 2010). Additionally, the present documents also align with the conception that brands are people and, consequently, they are metaphorically alive, as corporate identities are created and composed by individuals who are explicitly referred to using the pronoun "we" (Koller 2008). Finally, the semantic domain of fighting has already been noticed as recurrent (Koller 2005).

Specifically, Coke refers to stakeholders as three main groups (Figure 1): partners in general, franchise and bottling ones. Once again, the idea of working together towards a common purpose is implied by the terminological choice. Coke's final goal involves many parties in a process that could be 
defined as a co-creation of a good that has a value, concrete and/or symbolic for both the producer, at any stage of the production chain, and the final consumers of the good. "Customers" can be identified, indeed, as one of the roles in the document, where it appears twice, together with its synonym "consumers."

The collective effort to obtain the final product is also highlighted by the fact that the "people" working for the company are not only defined as employees, but as external collaborators too. Moreover, the agency conferred to workers is reminded by the invite made to them in the manifesto to "act like owners," meaning as if the corporation was totally in their control and interest. Hence, "owners" constitutes another role in the text. The "winning culture" expression with which Coke defines its mission, vision, and values, also represents a role in the text and can be read as part of the company itself. Considering all this, three levels on which roles develop can be identified, based on the vicinity of the entities to the corporation and its environment:

- Business level

- Closer level

- Further level

As evident, the first group is the most populated one, both in terms of number of occurrences and category density. The second most numerous circle is, conversely, the outer one.

Conversely, roles delineated in PepsiCo's manifesto (Figure 2) are almost double, being 101 in total, with the greatest majority of those concentrated in the middle area. In spite of the similarities in words, these do not show similar patterns as for their frequencies, especially for the inner circle: while Pepsi appears to focus more on a collective we, Coke seems to be willing to highlight its possessions more. This may respectively signal a major attention on people, intended as human capital from which the company benefits, both internally and externally, and on the control it is able to exercise on the environment surrounding it. In this sense, the recurrence of the same roles or comparable ones may be due to the parallels possible among the environments in which both companies are inserted. Those are characterized by the presence of identical or equivalent roles, identifying the individuals that populate the economic setting where the corporation operates.

Differences, though, seem to signal discrepancies in terms of strategic choices. For instance, as a stronger focus on the company and the people composing it for Pepsi and more attention devoted to Coke's potential and 


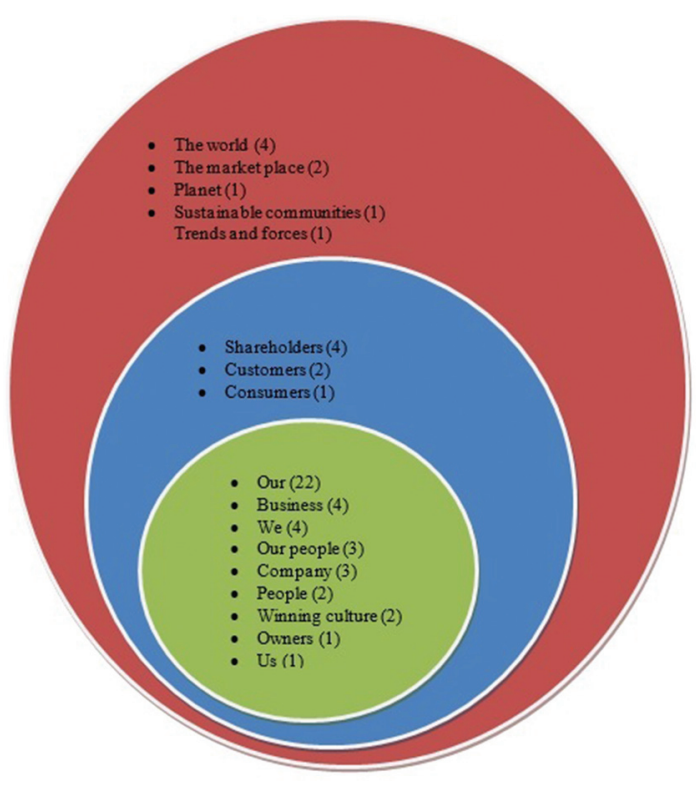

Figure 1: Coca-Cola's spatial dissemination of subjects through role attribution.

decisions on the other hand. Considering all this, it could be stated that the categorization proposed by Holland's model could allow pointing out both similarities and differences between texts, permitting both generalizations and specific analyses. With a reference to roles specifically, this category is vital to identify whoever is the agent of the action or undergoes a process and its repercussions. This investigation assumes a particular relevancy in businessrelated analyses, where necessities and dangers are the same in general, but they can be handled and strategically managed to build different types of interactions and reach diverse goals.

Especially, Coke appears to establish a set of guidelines for its own workers. Additionally, these texts seem to be destined to impact the corporations internally and externally as a code of ethics would potentially do, while explaining what ethical values and moral principles these companies would like and/or aim to follow throughout their business lives. Moreover, by defining these social actors, these documents also appear to clarify for their readers what are the relationships exiting among them and what repercussions those might have on the way these actors behave.

These interrelations can ultimately allow a deeper comprehension of texts, especially through their language. For example, making given word choices, employing a specific tone or establishing a precise relation text-context. Language is, indeed, an important constituent of social practice, as it can have a considerable 


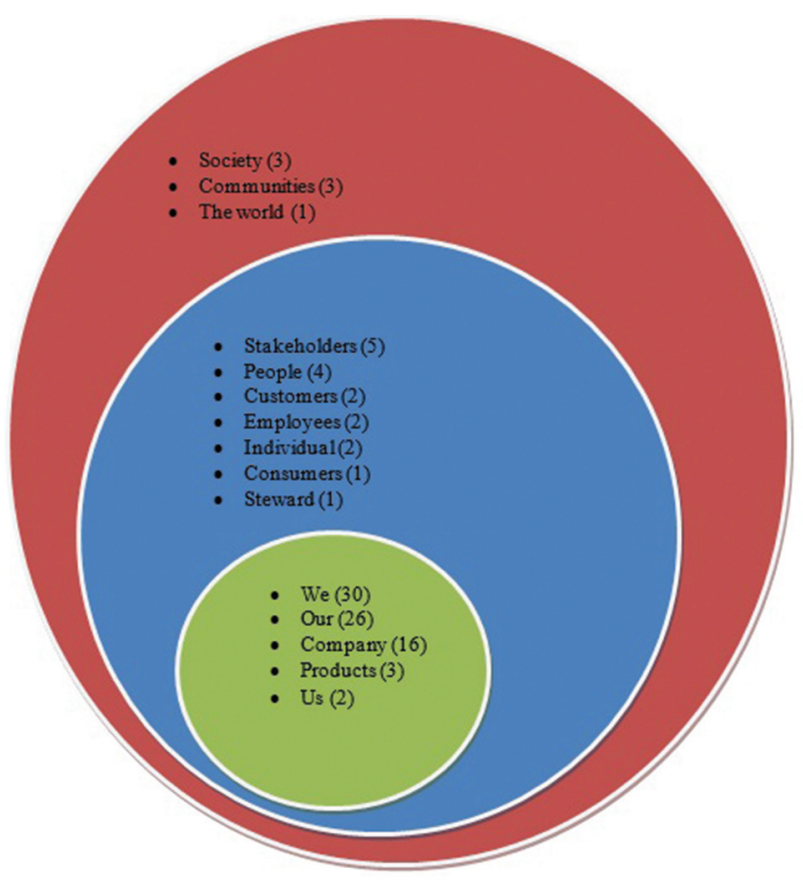

Figure 2: Pepsi spatial dissemination of subjects through role attribution.

impact on social interactions, by creating and positioning these agents in the social space (Garcia and Hardy 2007) and consequently influencing the readers' image of them or even their actions, ultimately potentially impacting their perception of reality as well (Fairclough 2001). Finally, the repetitive use of the collective we might aim to convey a perception of the corporations as "families."

\section{Discussion}

Coke's corporate manifesto is lacking in ethical norms, and the one value it does emphasize, responsibility, comes off more like a concerned father emphasizing personal duty. Coke's manifesto drives this ethical norm of responsibility through the use of words like integrity, commitment, and accountability, but this expectation of responsibility is mainly kept in-house. Hence, helping the community is only mentioned twice and never under the frame of responsibility.

On the other hand, Pepsi's ethical norms emphasize responsibility across the board to communities, shareholders, and the environment. Their Performance with Purpose mindset requires that the entire company project 
honesty, commitment, trust, diversity, and environmental stewardship at all times. Yet Pepsi's proactive value projection through its discourse of sustainability may only be providing a thin veneer of true ethical virtue (Swales and Rogers 1995). In 2011 PepsiCo. became part of a highly influential cluster of food lobbyists called the "Sensible Food Policy Coalition." This agency spent more than $\$ 60$ million on lobbying during the Obama administration's tenure to block "the food industry's voluntary guidelines for marketing to children" (Simon 2012). Another way Pepsi deflects from the fact they mainly sell unhealthy beverages is by employing "respected public health experts and medical doctors to represent the company." They even have an internal department titled "Global Health Policy," that is overseen by former employees of top institutions such as the US Centers for Disease Control and Prevention and the World Health Organization (Simon 2012).

While both manifestos stay true to their previous folklore predecessors (Coke's 2020 Vision and Pepsi's Performance Agenda), the intertextual usage of each document was different. Coke's manifesto revolved around the 2020 vision presenting itself as an addendum to, or extended commentary on it. Coke's manifesto picks out key headings from the 2020 Vision and reintroduces them as the main headings of the manifesto. Thus Coke's manifesto serves the purpose of filling in the absent details of what is meant by vague slogans such as "live our values."

Yet the Coke manifesto's goals are strikingly less economic than the ones presented in the 2020 Vision document. In fact, all of the goals in the manifesto text emphasize the people involved in the supply chain of the product and how they can contribute to making Coke's corporate superstructure run more effectively. In the 2020 Vision the goals are explicitly economic in nature, seeking to double the servings of the beverage to over "three billion a day" and "to more than double system revenue while increasing system margins.” This is a striking omission as Coke's vision of doubling its system's revenue necessitates meeting an ambitious 3-4\% annual volume growth. Interesting to note that the changes between the documents are not to give the manifesto a public face like Pepsi, but instead the changes reflect a more internally inclusive spirit giving exhortations to all those involved in the company's success while simply leaving out the financial goals so prominent in the 2020 vision.

Through application of the ideological content analysis we can observe the stark contrast between the two corporate manifestos that represent the most successful companies in the soft beverage industry. Coke projects highly exclusive discourse including only institutional insiders. Its corporate manifesto acts ideologically as an ethical discourse emphasizing personal responsibility, a utopian discourse that promises a future state of never ending creativity and optimism, and a strategic discourse that councils working smart through active 
problem solving. The role that dominated Coke's manifesto was "our” (22x), consequently the text reads as handful of corporate heads handing down admonitions to the work force. Basing the main headings of their manifesto on the 2020 Vision, they brought about a less concrete and more simplified version of the original as they left out any specific economic goals.

In contrast, Pepsi's manifesto represents a highly inclusive discourse that emphasizes honesty and commitment to sustaining people, the environment, and talent. Pepsi's utopian underpinnings draw upon the modern ideology of "progress" with its mantra of sustainable growth and superior financial success. The focus of strategic planning in the manifesto was providing financial rewards for investors and making wise decisions with company resources. "We" (30x) was the most occurring role with "our" (26x) following close behind. While the document is talking internally to its employees, its inclusion is expansive as it speaks about the company's relations with the community, society, and the world.

In conclusion, we have attempted to show how the FDM can pinpoint and deconstruct textual semantic units within corporate manifestos. As shown, the FDM rejects imposing a foreign checklist of what should or should not appear in a mission statement and instead uses five socio-semantic categories that take inventory of what appears in the text itself. The FDM as an ideological content analysis contributes new analytical tools for mission statement studies. Future applications of the FDM should be aimed at any primary document intending to mobilize collective action in the form of providing potential adherents with a readymade frame package complete with ethical norms, folklore narratives, utopian schemes, strategic plans, and collective roles.

\section{References}

Audi, Robert. 2009. Business ethics and ethical business. New York: Oxford University Press. Beaver, Graham. 2000. The significance of strategic vision, mission, and values. Strategic Change 9(4). 205-207.

Benford, R. D. \& D. A. Snow. 2000. Framing processes and social movements: An overview and assessment. Annual Review of Sociology. 26. 611-639.

Burr, Vivien. 2003. Social constructionism, 2nd edn. Routledge: New York.

Carroll, William K. \& R. S. Ratner. 1996. Master framing and cross-movement networking in contemporary social movements. Sociological Quarterly 37(4). 601-625.

Coca-Cola Company. n.d. Mission, vision \& values. http://www.coca-colacompany.com/ourcompany/mission-vision-values (accessed 8 October 2014).

Coca-Cola Company. n.d. 2020 vision. http://assets.coca-colacompany.com/22/b7/ ba47681f420fbe7528bc43e3a118/2020_vision.pdf (accessed 8 October 2014). 
Collins, James C. \& Jerry I. Porras. 1995. Building a visionary company. California Management Review 34(1). 30-52.

Collins, James C. \& Jerry I. Porras. 1997. Built to last. New York: Harper Business.

Fairclough, Norman. 1992. Discourse and social change. Cambridge: Polity Press.

Fairclough, Norman. 1995. Media discourse. London: Edward Arnold.

Fairclough, Norman. 2001. Language and power, 2nd edn. New York: Longman.

Fairclough, Norman. 2010. Critical discourse analysis: The critical study of language, 2 nd edn. New York: Longman.

Garcia, Patrica C. \& Cynthia Hardy. 2007. Positioning, similarity and difference: Narratives of individual and organizational identities in an Australian university. Scandinavian Journal of Management 23(4). 363-383.

Hart, Christopher. 2010. Critical discourse analysis and cognitive science: New perspectives on immigration discourse. New York: Palgrave MacMillan.

Holland, Jeremy J. 2014. Narrative fidelity to the Little Red Book in the framing efforts of the Red Guard Movement: A theoretical model for foundational documents. Discourse \& Society 25(3). 383-401.

Hongwei, He. 2012. Corporate identity anchors: A managerial cognition perspective. European Journal of Marketing 46(5). 609-625.

Kelly-Holmes, Helen \& Gerlinde Mautner. 2010. Language and the market. Basingstoke: Palgrave Macmillan.

Khalifa, Azaddin S. 2012. Mission, purpose, and ambition: Redefining the mission statement. Journal of Strategy and Management 5(3). 236-251.

Koller, Veronika. 2005. Critical discourse analysis and social cognition: Evidence from business media discourse. Discourse \& Society 16(2). 199-224.

Koller, Veronika. 2008. Lesbian discourses: Images of a community. London: Routledge.

Koller, Veronika. 2009. Corporate self-presentation and self-centeredness: A case for cognitive critical discourse analysis. In H. Pishwa (ed.), Language and social cognition: Expression of the social mind, 267-287. Berlin: de Gruyter.

Lévi-Strauss, Claude. 1963. Structural anthropology. Chicago: University of Chicago Press.

Lieblich, Amia, Rivka Tuval-Mashiach \& Tamar Zilber. 1998. Narrative research: Reading, analysis, and interpretation. Thousand Oaks, CA: Sage.

Lord, Jo. 2011. How to define and implement a vision for your company. Manager 75. 24.

Myers, Greg. 1994. Words in ads. London: E. Arnold.

Pepsi Co. n.d. Our mission and values. http://www.pepsico.com/Purpose/Our-Mission-andValues (accessed 8 October 2014).

Pepsi Co. n.d. Our performance with purpose goals. http://www.pepsico.com/Purpose/ Performance-with-Purpose/Goals (accessed 8 October 2014).

Plum, Werner. 1974. English utopian schemes, models of social and technological cooperation. Bonn-Bad Godesberg: Friedrich-Ebert-Stiftung.

Simon, Michele. 2012. A leopard like PepsiCo cannot change its spots. Guardian, March 12. http://www.theguardian.com/sustainable-business/blog/pepsico-corporate-social-respon sibility-public-health (accessed 8 October 2014).

Swales, John M. \& Priscilla S. Rogers. 1995. Discourse and the projection of corporate culture: The mission statement. Discourse \& Society 2(6). 223-242.

van Dijk, Teun A.1998. Ideology: A multidisciplinary approach. London: Sage. 